\title{
A Brief History of the Crack Tip Stress Intensity Factor and Its Application
}

\author{
Paul C. Paris \\ with the assistance of Thierry Palin-Luc
}

Arts et Metiers Paris Tech, Universite Bordeaux 1, LAMEFIP, Esplanade des Arts et Metiers, 33405 Talence Cedex, France

pcparis30@gmail.com

\begin{abstract}
The primary objective of this work is to discuss the origins, background and development of the elastic crack tip stress intensity factor, $K$, as they occurred. The further development of the three modes and the compilations of related formulas in the literature are discussed. The origins of applications to static crack growth stability, and sub-critical growth due to fatigue and environmental effects are included. Significant events such as the formation of the ASTM committee on Fracture Mechanics, the adoption of Damage Tolerance Analysis by the aircraft industry using Fracture Mechanics as a basis, and the further extension of the methods to large scale plasticity conditions are presented. Finally a discussion of early predictions of crack paths is discussed.
\end{abstract}

\section{INTRODUCTION}

The view of fracture from the point of view of mechanics was stated by Love [1] in his authoritative work on Theory of Elasticity in the 1890s by "The conditions of rupture are but vaguely understood,...” At that time Coulomb and Mohr's theories were followed by many without considering the effects of flaws or cracks in materials. Most often structural failures were analyzed by metallurgists who knew little about the mechanics of the effects of flaws. As a student in Engineering Mechanics in the early 1950s, there were studies of failure due to excessive deformations and various forms of instability but virtually nothing on fracture. Love's statement was still the case. However, the beginnings of background studies leading to modern "Fracture Mechanics" approaches for analyzing the growth of cracks were close.

Historically, some attempts were tried in the early 1900s but here only those connected to and leading directly to current methods will be mentioned. The first was that of Inglis [2] in 1913. He used elliptical-hyperbolic coordinates to solve the elastic stress problem of an elliptical hole in a plate. Then he tried to degenerate the ellipse into a crack and his stress solution near the crack tip became unresolved. With the assumption of a very small radius, $\rho$, at the tip of the ellipse of semi major axis, $a$, and a remotely applied biaxial stress, $\sigma$, applied, he did obtain the stress concentration, $\sigma_{\max }=2 \sigma \sqrt{a / \rho}$, and noted the difficulty that it encountered with 
considering, $\rho=0$. He was close to seeing that $\sigma \sqrt{a}$ was the important factor for flaw size effects, but in discussion did not observe that.

Later, in 1920 (and 1924) Griffith [3] used the full stress solution of Inglis to calculate $G$, the elastic potential energy made available in extending the crack per unit new crack area. He did experiments on amorphous glass, cleverly measuring the surface tension, $\gamma$, (energy per unit surface area) as the resistance to crack growth and elastic modulus, $E$, and predicted the value of $\sigma \sqrt{a}$ for crack glass tubes and spheres subjected to internal pressure using an energy balance approach. The critical energy balance for crack growth was given as: $\sigma \sqrt{a}=\sqrt{\frac{2 \gamma E}{\pi}}$, where the experimental values of fracturing strength of the left hand side averaged 239 and compared to independently evaluated measure of 133 for the right hand side. This was an astounding result for predicting the fracture strength from $\gamma$ and E. Good luck was also present since glass exhibits plasticity, resisting fracture, but this was perhaps compensated by a reduction in surface energy due to water adhesion on new glass surfaces, encouraging fracture. Moreover, Griffith undoubtedly was aided in this work with discussions with G. I. Taylor who was just down the hall at Cambridge and who communicated the paper to the Royal Society.

Between the 1920s and 1940s the attitude was present that Griffith's analysis applied only to perfectly brittle materials similar to glass and was often dismissed with metal fracture where obvious plastic dissipation of energy accompanied crack growth. However, in the late 1940s both Irwin [4] and Orowan [5] attempted to use the Griffith energy balance method to explain failures of metal structures, especially the T-1 Tankers and Liberty Ships which exhibited many failures during World War II. Indeed, Orowan noted that the plastic energy rate for cleavage fracture was more than 1000 times that for $\gamma$, but still gave predominately elastic failures in very large steel plates. So both hoped to be able to apply a Griffith type elastic energy balance with a plastic dissipation term added to assess fracture instability. The most applicable analysis of this came from papers by Irwin which culminated in his 1954 work [5]. Indeed I attended a Symposium on Plasticity in 1953 at Brown University with the great authorities present, where Captain Wendel P. Roop of the Navy discussed ship failures and indicated that to his best knowledge "running fracture failures had something to do with the energy available to drive the crack" but that anything further was still vague. No one had any comments, which he solicited to explain his statement. As a student in Mechanics I remained perplexed that the fracture failures of structures were still "vaguely understood".

\section{THE DEVELOPMENT OF THE CRACK TIP STRESS FIELD CONCEPT}

At the U. S. Naval Research Laboratory (NRL), where Irwin was Superintendant of the Mechanics Division, the group of people who assisted him were capable help in his work on fracture analysis. In addition A. A. Wells then at the Brittish Welding Institute made frequent lengthy visits in the early 1950s to NRL and drew his attention to a method solving elastic crack problems by Westergaard [6]. Irwin [7] used this to obtain the significant singularity term in the elastic crack tip stress field series expansion. The form, which he first published was: 


$$
\sigma_{i j}=\left(\frac{E G}{\pi}\right)^{1 / 2} \frac{f_{i j}(\theta)}{\sqrt{2 r}}+\text { terms of } r^{1 / 2} \text { and higher }
$$

( except for a constant term $\sigma_{0}$ parallel to the crack )

where $r$ is measured from the crack tip, $\theta$ is measured from the extension of the crack line, and $G$ is the Griffith available elastic energy rate per unit new crack extension area or the so called "crack extension force". For a uniformly stressed sheet the original "elastic crack tip stress intensity factor" is $\left(\frac{E G}{\pi}\right)^{1 / 2}=\sigma \sqrt{a}$, where in later times Irwin moved the $\pi$ to the other side of the equation to define the current "crack tip stress intensity factor" as $K=(E G)^{1 / 2}=\sigma \sqrt{\pi a}$. Again the significance of $\sigma \sqrt{a}$, as an expression of the fracture size effect, for the crack in the uniformly stressed sheet (for the Griffith configuration) is noted. In addition Irwin gave the solutions for several other configurations in this paper. Incidentally, Irwin used " $K$ ” to denote the stress intensity factor to honor his long time friend and colleague Joseph A. Kies.

Meanwhile, just after Irwin's publication (see submission dates of the papers), Williams [8] had done a polar-coordinate eigen-function elastic solution of the crack tip field in a somewhat similar fashion to Irwin but had not enterpreted its relation to Griffith's work and its further implications. However, the first known expansion of the crack tip stress field was done by Sneddon [9] in 1946 for the "penny shaped crack”, without realizing its important implication to fracture analysis.

The fact that different configurations of crack geometries and loading methods all had the same local crack tip stress fields differing only in intensity, as indicated by the form of the crack tip intensity factor, explained many previously unresolved questions. For example with small scale yielding conditions (low nominal stresses on the uncracked remaining section), one could reason that the plastic zone would be completely embedded within the elastic crack tip stress field and would therefore be similar between various crack configurations and identical for equal crack tip stress intensity values for a given material and ambient conditions. This also explained the thickness effect on the toughness of plates with through cracks in terms of plane stress and plane strain, Paris [10] and Irwin [11] and the apparent (or effective) elastic crack size as increased by the influence of plastic zone. Further, in an encyclopedic source Irwin [12] also defined the three modes of crack tip stress fields and the elastic analysis methods to determine their stress intensity factors, $K_{I}, K_{I I}, K_{I I I}$. These results were further extended by Irwin [13] published in 1960. The definition of the elastic crack tip stress intensity factors and their corresponding stress fields was then complete. These results were soon put to use in analyzing static failure of precracked test pieces by various researchers.

\section{THE INVOLVEMENT OF THIS AUTHOR}

In June 1955 just after I received my MS degree, I took a Faculty Summer Position with the Boeing Company in Seattle. It was a first experience with industry. They asked me to study fracture in order to be sure the 707 commercial transport aircraft would not experience the type of failures that had occurred with the pressure cabins of British Comets. May I admit now that I knew nothing about fracture but was afraid to admit it then. The initial reaction was to read as much as possible on the subject, about 120 papers in the first weeks there. Most of those papers made no sense at all to 
someone schooled in Mechanics. The only reasonable ones seemed to be those of Irwin! With that background I requested some tests of the various thicknesses of pressure cabin skin materials of both the 707 and KC135, its sister Air Force tanker aircraft. A very surprising result was that the 707s material, 2024T-3, increased in fracture toughness with increasing thickness, whereas the 7075T- 6 of the KC135 decreased in toughness with increasing thickness. Moreover, the 2024 was also much superior compared to 7075 in fracture resistance for equal thicknesses. The following winter the Chief of Structural research asked me to attend the AIAA national meeting where he was presenting a paper using my data from these tests with no credit to me. I was requested to be there to answer questions he might be asked. My reluctant appearance for his presentation changed to enthusiasm after the meeting, when he asked me to become a special consultant to Boeing, while still a graduate student at Lehigh University. Consequently, I had funds to visit Irwin at the Naval Research Laboratory and continue my fracture studies. Irwin always welcomed my visits and our inspiring discussions, exchanging thoughts on how to understand our observations of cracking. My resolution of the thickness effects was that it was caused by the constraint of plane strain vs. plane stress in the plastic zone at the crack tip, [10]. Irwin [11] agreed and later published his own data on thickness effects in 1960. My consulting and summer trips to Boeing continued into 1957. That fall I took a position at University of Washington in Seattle to be closer to Boeing with a part time position there as well.

Early in this Boeing experience, in 1955, Dr. E. Rowe of Boeing asked me if the Griffith-Irwin energy balance method could help to understand fatigue crack growth. My initial reaction was that fatigue crack growth could not be explained by the energy balance method. Later in 1957 when I first saw the crack tip stress field equations my reaction was immediate that the fluctuation of the crack tip stress intensity factor, $K$, causing fluctuations of the crack tip stress field surrounding the plastic zone could correlate growth rates [10]. At that time we had no data to prove that approach. However by 1959 we had data from three independent sources on growth rates in 2024 and 7075 Aluminum Alloys and correlated the rates for each alloy. We wrote a paper showing the correlations using $K$ and had it rejected by three leading journals. It then became the subject of my doctoral dissertation at Lehigh University where Boeing gave me funding to expand that research. It grew into a whole group working on various aspects of Fracture Mechanics, which had a significant impact on the overall growth of that field. Later in the development of that group Irwin became a Boeing University Distinguished Professor at Lehigh as well.

\section{THE ASTM SPECIAL COMMITTEE}

Late in the 1950s the American Society for Testing Materials (ASTM) was asked by the military to form a special committee to resolve fracture problems with the Polaris Submarine missile. They called together all of the about 10 top Fracture Mechanics experts at that time to participate. The meetings not only worked on resolving the missile issue but also resulted in this group exchanging research ideas and data by special presentations to each-other. It greatly accelerated progress in the whole field. Later it became the regular committee E-24 which developed the testing method for $K_{I C}$, plane strain fracture toughness, labeled method E-399. Moreover the committee produced a book, ASTM-Special Technical Publication 381, "Fracture Toughness Testing” [14] containing the basic background knowledge, testing methods and 
practical applications. It provided a comprehensive state of the art assessment of the field in 1964. My own contribution in that book was a first extensive compilation of crack stress analysis formulas and methods, which was later superceded by the Tada [15] Handbook.

Again, Irwin [16] contributed by providing the solution for the elliptical shaped crack. He did so by taking the displacement solution for an ellipsoidal cavity and degenerated the ellipsoid into a flat crack after finding that the stress solution was untenable. He also developed a solution for the edge crack, which checked and drew attention to the solution from Wigglesworth [17]. These were key to developing $K$ approximations for the part through semi-elliptical surface flaws for many significant practical applications, missile cases, etc. Other significant contributions are to numerous to list here ( see [15] ), however those of Koiter [18], obtaining $K$ by assymtotic expansions; Bueckner [19] with his weight functions; Isida [20] using series mapping methods; and finally Newman [21] for numerical methods for surface flaws deserve special attention.

These efforts on obtaining $K$ formulas and methods for their development provided the ASTM E-24 committee with necessary background to develop standard test methods for static failure and beyond for sub-critical crack growth.

\section{THE EARLY APPROACHES TO SUB-CRITICAL CRACK GROWTH}

By the time the first publication on fatigue crack growth using $K$ occurred [22], it was realized that for subcritical growth the nominal stresses are lower than for static failure and that the reversed cyclic plastic zone in fatigue was smaller by another factor of 4 so that the linear elastic fracture mechanics method was much better than for applications to static failure. Further, problems, which occurred due to environmental crack growth under static loading, were most prevalent in extremely high strength metal alloys. H. H. Johnson's original work in this field was done on H11 tool steel for example, see his earlier references in [23]. He was the first to show that for fatigue precracked tests, $K$ could correlate static environmentally induce growth rates from specimens at various nominal stress levels. He also demonstrated that the activation energy for growth corresponded to that for hydrogen diffusion in the metal lattice. It was somewhat later that B. F. Brown of the Naval Research Laboratory did simple precracked cantilever beam tests and observed the threshold for static environment cracking, $K_{I S C C}$. Similarly, in the late-1960s Piper of Boeing showed the precracked threshold $K_{I S C C}$ for 8-1-1 Titanium Alloy in salt water was less than $20 \%$ of the static plane strain fracture toughness, $K_{I C}$ for this alloy. Only slightly above that threshold, $K_{I S C C}$, the growth rates were more that an inch per hour. Prior to these tests 8-1-1-Ti alloy was a candidate material for submarines and the U.S. commercial supersonic transport aircraft (never built). This material was also used for R. Bucci's [24] dissertation to demonstrate environmentally enhanced fatigue crack growth rates of this material in salt water of as much as 1000 times faster than that in inert environment. These sub-critical applications all showed that linear elastic fracture mechanics employing $K$ was clearly more accurately applied than for static failure.

Also in the mid-1960s Lindner [25] found a fatigue crack growth threshold, $\Delta K_{\text {threshold }}$ in 7075 aluminum alloy, i.e. a level of $\Delta K$ below which no growth occurs. Later it 
was verified that the threshold does exist, but its definition is clouded by "overload crack closure effects", which may corrupt its true level. Such matters are still in dispute [26]. However the work of Elber [27] originally demonstrated that crack closure has a significant effect on fatigue crack growth rates. Much has been learned about closure since Elber's work in the late 1960s. This is perhaps best displayed by Newman's [28] finite element strip yield model of crack growth analysis with variable amplitude loading. However, much is left to be better understood in this area.

\section{DAMAGE TOLERANCE OF AIRCRAFT AND OTHER APPLICATIONS}

In late 1969 the event of a crash of a U. S, Air Force F-111 aircraft created a key use of Fracture Mechanics in fixing and continued use of that aircraft with safety. The solution involved "proof testing" at a high load to assure that no cracks larger than a certain size are present. Then, for the largest of cracks, which would not fail during the proof test, environmentally enhanced fatigue crack growth calculations were made to ensure a calculated amount of safe flying life. With the success of this method based on Fracture Mechanics calculations the U. S. Air Force made such methods a design basis for all existing and future aircraft. Soon thereafter, the U. S.- F. A. A. made such requirements also mandatory for all commercial aircraft. Damage Tolerance Analysis became one of the largest applications of Linear Elastic Fracture Mechanics based on the crack tip stress intensity factor, $K$.

Of course many other applications to various structural problems occured before the mid-1970s. A typical example were pressure vessels where a "Leak Before Break" approach could be used involving, $K$, as a basis of the analysis. The Nuclear Pressure Vessel Code adopted an analysis using an assumed 1/4 of the wall thickness surface flaw $K$ analysis and $K_{I C}$ values adjusted for material, temperature and irradiation damage to assure safety. Again the many other applications are too numerous to be listed here.

\section{SPECIAL EXTENSIONS OF ELASTIC STRESS INTENSITY ANALYSIS}

Beyond the analysis of the single dominant singularity at a sharp elastic crack tip, the additional series terms can be evaluated. The first of these is often called the T-stress or $\sigma_{0}$, mentioned earlier with Irwin's crack tip field equations. In addition there are the next terms in the series expansion of Irwin's tip field method that should receive equal attention [29]. Moreover, for blunted cracks the elastic field was computed by Creager [30,15] in his dissertation, which simply adjusts the center of the polar coordinates ( to the focal point of a sharp ellipse or parabolic opening shape ) within the notch. These extensions of the crack tip stress intensity concepts have received little attention.

\section{FRACTURE MECHANICS FOR HIGH TOUGHNESS MATERIALS}

Materials with high fracture toughness, $K_{I C}$, and relatively low yield strength are often not appropriate for analysis by linear elastic methods. There, static fracture may occur only after net section yielding for many applications consequently linear elastic methods are not appropriate. At the ASTM meeting in 1964, which produced STP381 , a conclusion in the discussion period was that it would not be possible to treat 
such topics for at least ten years before such analysis ( as soundly based as linear elastic, $K$-methods ) might become available.

The prevailing method was first devised by Rice [31], who defined $J$ as an integral form, which is the intensity factor of crack tip plastic stress field for power hardening material. The field is:

$$
\sigma_{i j}=\sigma_{0}\left(\frac{J}{\sigma_{0} \varepsilon_{0} r}\right)^{\frac{n}{n+1}} \Sigma_{i j}(\theta, n)
$$

where $\mathrm{n}$ is the power hardening coefficient in the stress-strain law of the type: $\frac{\varepsilon}{\varepsilon_{0}}=\left(\frac{\sigma}{\sigma_{0}}\right)^{n}$. This so called HRR field was found by both Rice [32] and Hutchinson [33]. It is noted that for $n=1$ (linear elastic material) this field reduces to the Irwin field equations (1), noted earlier, where $J=G=\frac{K^{2}}{E}$. Therefore Irwin's field equations are simply a special case of this more general plastic crack tip stress field equations and intensity factor, $J$. They have been used in the early to mid 1970s to characterize static fracture instability, fatigue crack growth, creep crack growth, etc., which shall be regarded as beyond the scope of this discussion.

\section{THOUGHTS ON CRACK PATHS AND ABRUPT CHANGES IN DIRECTION}

We have all seen cracks which change their direction of growth both slowly as they grow and abrupt changes in direction. In 1963 Erdogan [34] published some test results for inclined crack in tension and concluded that the crack extended changing abruptly to the direction of maximum circumferential tension as calculated from the elastic crack tip stress equations. This conclusion caused me to withdraw my name as a coauthor of this work. The plastic material, which was tested, exhibited substantial plasticity so that the real crack tip stresses would undoubtedly not be at exactly that same angle for maximum circumferential tension. Indeed if the material would have been perfectly brittle the abrupt change in direction would have been to that which would give maximum energy release to overcome the cracks resistance, $\gamma$, exactly the energy per new surface created as Griffith proposed. However with a plastic stress field and no means of calculating the maximum energy direction at that time or the maximum circumferential stress direction or the maximum of any speculated critical quantity proposed, it was not appropriate to make any claims about a proposed reason for the "crack path" taken.

Further with materials that exhibit plasticity, slow stable growth prior to crack instability is always the case, therefore the R-curve of material's resistance is a necessary approach to changes in direction toward an instability. It is admitted here that such an analysis is so very complex that it looks quite unlikely. Perhaps some light will be shed on this matter here?

For fatigue crack growth matters become even more complex with cycling of loads. Intuition has made it seem that in fatigue the crack extends toward directions that tend to be first mode cracking ( $K_{I I}=K_{I I I} \rightarrow 0$ ) as the crack progresses. Of course this intuitive proposal is pure speculation. Beyond these thoughts better analyses will be welcomed here. 


\section{ACKNOWLEDGEMENT}

The author acknowledges the Arts et Metiers Paris Tech and Foundation Arts et Metiers for the financial support of Paul C. Paris' stay at LAMEFIP in 2009. The encouragement of Professor Ivan Iordanoff, Director of LAMEFIP, is also acknowledged with thanks.

\section{REFERENCES}

[1] Love, A. E. H., A Treatise on the Mathematical Theory of Elasticity, Dover, New York, p121, 1944, (4 ${ }^{\text {th }}$ ed. reproduced), (Editions 1893,1906, 1920,1927).

[2] Inglis, C. E., Proceedings Inst. Naval Architects, Vol. 60, 1913.

[3] Griffith, A. A., Phil. Trans. Roy. Soc., London, Series A. Vol.221, p. 163, 1920.

[4] Irwin, G. R., in Fracture of Metals, Amer. Soc. Metals, 1948.

[5] Irwin, G. R. and Kies, J. A.,The Welding Journal, Res. Suppl.Vol. 33, p.193,1954.

[6] Westergaard, H. M., Trans. of ASME, J. A. Mech., Series A,Vol.66, p.49, 1939.

[7] Irwin, G. R., Trans. of ASME, Jour. Appl. Mech.,Vol 24, p.361, 1957.

[8] Williams, M. L., Trans, of ASME, J. A. Mech.,Vol. 24, p.109, 1957.

[9] Sneddon, I. N., Proc. Roy. Soc. London, Ser. A, Vol.187, p.229, 1946.

[10] Paris, P. C., Document D2-2195, The Boeing Company, 1957.

[11] Irwin, G. R., Jour. Basic Engin., Trans. ASME, Ser.D, Vol.82, No.2,p.417, 1960.

[12] Irwin, G. R., Fracture, Handbuch der Physik., Vol. VI, p. 551 Springer, 1958.

[13] Irwin, G. R., Proc. of $1^{\text {st }}$ Symp. on Naval Struct. Mech., p.557, Pergamon,1960.

[14] Paris, P. C., in Fracture Toughness Testing and Its Applications, Proceedings of the Symposium in Chicago in June 1964, ASTM STP 381, 1965.

[15] Tada, H., Paris, P. C. and Irwin, G. R., The Stress Analysis of Cracks Handbook, $3^{\text {rd }}$ edition, ASME Press, 2000.

[16] Irwin, G. R., Trans. of ASME, Jour. Appl. Mech., Vol. 29, p.561,1962.

[17] Wigglesworth, L. A., Mathematica, Vol. 5, p. 67, 1957.

[18] Koiter, W. T., Trans. of ASME, J. A. Mech., Vol.32, p. 237, 1965 \& also in [15].

[19] Bueckner, H. F., ZAMM, Vol. 50, p. 529, 1970 \& also in [15].

[20] Isida, M., Engineering Fracture Mechanics, Vol. 7, p. 505, 1975 \& also in [15].

[21] Newman, J. C. Jr., ASTM STP 687, p.16, 1979.

[22] Paris, P. C., Gomez, M. P., and Anderson, W. E., The Trend in Engineering, University of Washington (Seattle), 1961.

[23] Johnson, H. H., and Paris, P. C., Engin. Fract. Mech., Vol.1, No.1, Paper 1, Pergamon Press, 1968.

[24] Bucci, R., PhD. Dissertation, Lehigh University, (P. C. Paris director), 1970.

[25] Lindner, B., MS Dissertation, Lehigh U., (P. C. Paris director), 1965.

[26] Newman, J. C. Jr., Private Communication 2008.

[27] Elber, W., Journal of Engineering Fracture Mechanics, 1970

[28] Newman, J. C. Jr., Comprehensive Structural Integrity, Vol. 4, Elsevier,2003.

[29] Paris, P. C., and Tada, H., Proc. of Internat. Conf. on Fatigue Dam. to Struct. Materials V, Internat. Jour of Fatigue, 2005.

[30] Creager, M., and Paris, P. C., Int. Jour. of Fract. Mech., Vol. 3, p. 247, 1967.

[31] Rice, J. R., Trans. of ASME, Jour. Appl. Mech., Vol. 35, p.379, 1968.

[32] Rice, J. R., and Rosengren, G. F., Journ. of Mech. and Phys. of Solids, Vol.16, p. $1,1968$.

[33] Hutchinson, J. W., Journ. of Mech. and Phys. of Solids, Vol.16, p. 13, 1968.

[34] Erdogan, F., and Sih, G. C., Trans.of ASME, Ser. D, Vol. 85,p. 519, 1963. 